\title{
Holographic imaging during transcatheter aortic valve implantation procedure in bicuspid aortic valve stenosis
}

\author{
Wykorzystanie hologramu podczas przezcewnikowego wszczepienia zastawki \\ aortalnej u pacjenta ze stenozą dwupłatkowej zastawki aortalnej
}

\author{
Bartosz Rymuza ${ }^{1}$, Kajetan Grodecki ${ }^{1}$, Jakub Kamiński ${ }^{2}$, Piotr Scisło ${ }^{1}$, Zenon Huczek ${ }^{1}$ \\ ${ }^{1} 1^{\text {st }}$ Department of Cardiology, Medical University of Warsaw, Warsaw, Poland \\ 2Faculty of Physics and Applied Computer Science, AGH University of Science and Technology, Krakow, Poland
}

We present a case of an 80-year-old male patient with symptomatic aortic stenosis, admitted to the $1^{\text {st }}$ Department of Cardiology, Medical University of Warsaw for valve replacement. His prior medical history included: non-obstructive coronary artery disease, transurethral prostatectomy, right-sided hernia, and right-sided nephrolithiasis surgery. Transthoracic echocardiography showed mean aortic pressure gradient of $40 \mathrm{~mm} \mathrm{Hg}$, aortic valve area (AVA) of $0.77 \mathrm{~cm}^{2}$, and peak velocity of $4.3 \mathrm{~m} / \mathrm{s}$. For precise aortic annulus measurement, transoesophageal echocardiography (TEE) and a multi-sliced computed tomography (MSCT; Fig. 1) scan were performed. On TEE the aortic annulus perimeter was $83 \mathrm{~mm}$, with diameters $24 \times 29 \mathrm{~mm}$. On MSCT annulus perimeter was $87 \mathrm{~mm}$ with diameters of $23 \times 32 \mathrm{~mm}$. Both imaging tech-

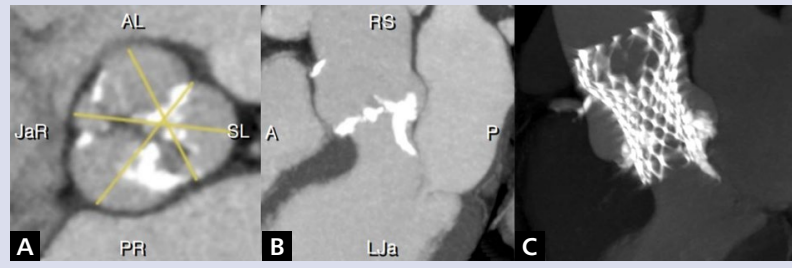

Figure 1. Multi-sliced computed tomography (MSCT) curved three-dimensional multiplanar reconstruction (3D MPR); A. Cross-section of the aortic valve at the level of the sinus of Valsalva showing bicuspid anatomy with raphe between left and right coronary cusps; B. Preprocedural 3D MPR maximal intensity projection (MIP) showing heavily calcified aortic valve with calcification extending into the left ventricular outflow tract; C. Post-procedural 3D MPR MIP with correct apposition of implanted bioprosthesis

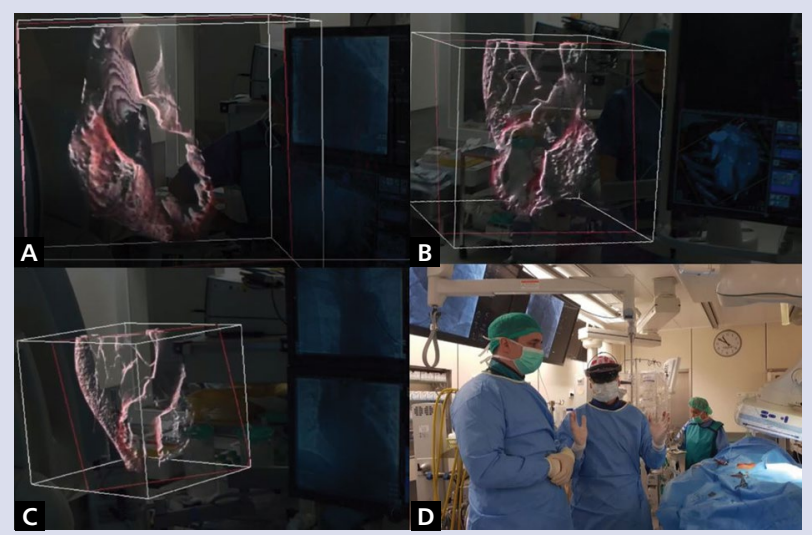

Figure 2. A-C. Holographic images of the heart and aortic valve anatomy as seen by the operator wearing HoloLens ${ }^{\circledR}$ headset; D. View of the operating room with operator interacting with holographic imaging niques revealed that the patient had bicuspid aortic valve with raphe between left and right coronary cusps (Type I $\mathrm{L}-\mathrm{R}$ ) and protruding calcium to the left ventricular outflow tract. The "prospected" annulus perimeter based on MSCT was $79.3 \mathrm{~mm}$. The patient was referred by the local Heart Team to transcatheter aortic valve implantation (TAVI) via the femoral route. To better visualise the complex anatomy of the patient with bicuspid AS the use of holographic imaging was applied. CarnaLife Holo ${ }^{\circledR}$ (MedApp S.A., Krakow, Poland) visualises the individual patient's heart as an interactive holographic image based on computed tomography $(\mathrm{CT})$ or a magnetic resonance imaging (MRI) scan of the patient (Fig. 2A-C). Possible interactions using voice commands and hand gestures include visualising the structure of the heart (3D), also during its cardiac cycle (4D), slicing, and partitioning. Users see and interact with those images via a Microsoft HoloLens ${ }^{\circledR}$ head-mounted display (Fig. 2D), which creates the visual illusion of a solid 3D object by recreating depth cues (perspective, occlusion, convergence, and parallax). The software supports loading of the medical data sets in common DICOM file format and adjusting the transfer function to achieve effective visualisation of skin, hard tissues like bones, and soft tissue organs like heart, based on methods well-established in the medical visualisation field. This method allows for the use of raw medical data acquired from CT and MRI devices, in contrast to the common approach with additional surface reconstruction to polygonal models, as in the case of typical surgery approaches with head-mounted displays. The periprocedural use of CarnaLife Holo ${ }^{\circledR}$ enabled the operator to view holographic image during the course of the procedure, facilitating precise visualisation of the aortic root. Ultimately the patient was implanted with a $29-\mathrm{mm}$ Evolut R (Medtronic Int.) valve with small paravalvular leak (AVA $1.74 \mathrm{~cm}^{2}$, mean pressure gradient $9 \mathrm{~mm} \mathrm{Hg}$, Vmax $2.4 \mathrm{~m} / \mathrm{s}$ ) and no conduction disturbances. The patient was discharged home on day 2 after the procedure in good clinical condition.

\section{Address for correspondence:}

Kajetan Grodecki, $1^{\text {st }}$ Department of Cardiology, Medical University of Warsaw, ul. Banacha 1a, 02-097 Warszawa, Poland, e-mail: kajetan.grodecki@gmail.com

Conflict of interest: J. Kamiński is employed by MedApp SA; Z. Huczek is proctor and speaker for Medtronic Int.

Acknowledgements: Authors would also like Prof. Krzysztof J. Filipiak (1 ${ }^{\text {st }}$ Department of Cardiology), Michat Adamczyk and Mateusz Kierepka (both, MedApp SA) for providing the technology and enabling fusion imaging.

Kardiologia Polska Copyright (c) Polskie Towarzystwo Kardiologiczne 2017 